\title{
PREMATURE DELIVERY UNDER 32 WEEKS OF GESTATION - CASE CONTROL RETROSPECTIVE STUDY
}

\author{
RADU CHICEA ${ }^{1}$, IOANA CODRUȚA LEBĂDĂ ${ }^{2}$, MARIA LIVIA OGNEAN ${ }^{3}$ \\ 1,2,3 “Lucian Blaga” University of Sibiu, ${ }^{1,3}$ Sibiu County Emergency Clinical Hospital
}

Keywords: $\quad$ premature Abstract: Prematurity is a major health problem and it is an important life-threatening pathology for delivery, 32 weeks, the children in their perinatal, new-born and infantile period. We have evaluated the epidemiologic epidemiology prognosis factors for prematurity in Obstetrics Clinic of Sibiu city. We have analysed the epidemiology of 649 preterm babies between 2012 and 2019 in a III grade Maternity Clinic concerning general maternal information, pregnancy pathology and delivery. We have found significant differences between single and multiple pregnancies and between natural conceived pregnancies and assisted reproductive techniques conceived pregnancies concerning the maternal age, number of cortisone doses, modality of delivery and significant differences between normal conceived and assisted reproductive technique conceived new born related to maternal age and pregnancy and labor fetal presentations dystocia. As a conclusion, prematurity is induced by high blood pressure, pregnancy bleeding and infectious complications. Prophylactic cortisone is improving fetal outcome and is a routine practice in our clinic.

\section{INTRODUCTION}

The incidence of prematurity is dramatically influenced by the quality of prenatal medical network involved in the evaluation, treatment and follow up of the pregnancies.

The incidence of prematurity in Romania is around $10 \%$, sometimes even higher going to $12,5 \%$ and it is considered to be much higher than in the western countries of Europe.(1) The main complications that affect and have a major influence the neonatal prognosis and the long-term prognosis of the premature new born are acute respiratory failure, intraventricular hemorrhages, necrotic enterocolitis, late neonatal sepsis, retinopathy of prematurity, chronic lung disease etc.

The most important factor involved in improving the prognosis of high-grade prematurity is significant investment in the health system. Japan is one of the countries which had a poor prognosis for prematurity and has become one of the most advanced health care system for pregnant and neonatal health care. The main aspects changed for improving the neonatal the prognosis are: maternity birth, the emergence and development of neonatal intensive care services, mechanical ventilation and monitoring of neonatal vital parameters, surfactant therapy, pulse oximetry and high-frequency oscillatory ventilation (HFOV).(2)

\section{AIM}

Evaluation of epidemiological factors in premature births under 32 gestational weeks in the Obstetrics and Gynecology Clinic of Sibiu

\section{MATERIALS AND METHODS}

All premature babies born in Obstetrics and Gynecology Clinic Sibiu or transferred to our unit (level III) between 2012 and 2019 were included in the study.

Exclusion criteria: readmissions for maternal/ neonatal problems

Neonatal features and postnatal complications among premature infants under 32 weeks were compared; the data were collected from the section's electronic database.

There were collected general information about the pregnancies and information about the determination and favouring factors for premature delivery. Fetal outcome factors were also collected.

Statistical analysis was performed using SPSS for Windows 19.0; $\mathrm{p}$ was considered statistically significant $<0.05$; ORs were calculated for $95 \% \mathrm{CI}$

\section{RESULTS}

During the period of study, in the Obstetrics and Gynecology Clinic of Sibiu, there were assisted for delivery and were transferred 649 premature new-borns under 32 weeks of gestation. From 583 births the average gestational age of the lot was $29.6+/-2.4$ (median 30.6), and the average weight was $1347.02+/-315.7$ (median 1360). According to the weight for the gestational age there were adequate for gestational age 252 $(38,8 \%)$, small for gestational age $335(54,6 \%)$ and large for gestational age $63(9,74 \%)$.

The distribution of the maternal age is presented in table no. 1

Table no. 1. Distribution of the maternal age

\begin{tabular}{|l|c|}
\hline \multicolumn{1}{|c|}{ Maternal age } & Number \\
\hline$<18$ & 56 \\
\hline $19-34$ & 475 \\
\hline $35-39$ & 118 \\
\hline$>40 \quad 23$ \\
\hline
\end{tabular}

${ }^{1}$ Corresponding author: Radu Chicea, Str. N. Beldiceanu, Nr. 9, Sibiu, România, E-mail: radu.chicea@ gmail.com, Phone: +40744 695310 Article received on 10.10.2021 and accepted for publication on 02.12.2021 


\section{CLINICAL ASPECTS}

important factor in etiology of prematurity the distribution is presented in table no. 2 .

Table no. 2. Distribution of gestation and parity numbers

\begin{tabular}{|l|l|l|l|}
\hline \multicolumn{2}{|c|}{ Gestations } & \multicolumn{2}{c|}{ Parity } \\
\hline 1 & 170 & 1 & 244 \\
\hline $2-4$ & 285 & $2-4$ & 274 \\
\hline$>5$ & 128 & $>5$ & 65 \\
\hline
\end{tabular}

An important factor which was considered for the etiology of prematurity was the number of the fetuses. The data are presented in table no. 3 .

Table no. 3. Number of the fetuses for a pregnancy

\begin{tabular}{|l|l|l|}
\hline \multicolumn{1}{|c|}{ Number of fetuses } & \multicolumn{1}{c|}{ Number of cases } & \multicolumn{1}{c|}{$\%$} \\
\hline 1 & 484 & 82,9 \\
\hline 2 & 97 & 16,6 \\
\hline 3 & 2 & 0,3 \\
\hline
\end{tabular}

The weight of the new-borns at the delivery is presented in table no. 4 .

Table no. 4. The distribution of new born weight at birth

\begin{tabular}{|l|c|}
\hline \multicolumn{1}{|c|}{ Weight at delivery } & Number \\
\hline$<500 \mathrm{~g}$ & 4 \\
\hline $501-750 \mathrm{~g}$ & 40 \\
\hline $751-1000 \mathrm{~g}$ & 97 \\
\hline $1001-1250 \mathrm{~g}$ & 122 \\
\hline $1251-1500 \mathrm{~g}$ & 155 \\
\hline $1501-1750 \mathrm{~g}$ & 135 \\
\hline $1751-2000 \mathrm{~g}$ & 67 \\
\hline $2001-2500 \mathrm{~g}$ & 29 \\
\hline
\end{tabular}

As the number of the fetuses is influenced significantly by the assisted reproductive techniques (ART) such as ovulation induction and vitro fertilization (IVF) the number of pregnancies obtained by ART were evaluated separately. The distribution is figured in table no. 5 .

Table no. 5. The modality of obtaining the pregnancy

\begin{tabular}{|l|l|l|}
\hline Type of pregnancy & Number & $\%$ \\
\hline ART & 24 & 3,9 \\
\hline Natural & 560 & 96,1 \\
\hline
\end{tabular}

Premature delivery is also associated with different types of pathology. The most frequent pathology found associated with the prematurity under 32 weeks of gestation were: diabetes $4(0,7 \%), 3$ with prenatal existence, 1 as gestational diabetes, high blood pressure HTA 45 (7,7\%), 7 chronic hypertension, 38 with pregnancy induced hypertension, preeclampsia and eclamsia in 17 cases $(2,9 \%)$, coriaoamniotitis 6 cases $(1 \%$, hemorrhage during pregnancy and labour $54(9,3 \%)$, other pathology in 281 cases $(48,2 \%), 160$ cases $(27,4 \%)$ by imminent premature birth and 35 cases $(6 \%)$ by urinary infections.

Cortico-therapy is essential in the prevention of fetal respiratory distress. In our study the cortico-therapy was administered and initiated as soon as possible. The situation is this: the average gestational age at the administration of corticotherapy $30.5 \mathrm{SG}+/-2.4$ weeks, prenatal corticosteroid therapy $334(57.2 \%)$, number of doses: 1 dose - 91 (15.6\%), 2 doses - 54 (9.3\%), 3 doses $-38(6.5 \%), 4$ doses $-143(24.5 \%), 5$ doses -5 $(0.9 \%), 6$ doses $-1(0.2 \%), 8$ doses $-2(0.3 \%)$, complete cure 151 , incomplete treatment -183 .

The average duration of corticosteroid treatment was also determined. The average birth age for the premature newborn was of $30.7+/-79$ hours. Usually, the corticosteroid used was Dexamethasone in 310 cases and hydrocortisone acetate in 24 cases.

There are important obstetrical factors analysed in our study with important influence in the maternal and new-born prognosis:

Presentation

- Cranial - $490(75.5 \%)$
- $\quad$ Other (pelvic, transverse) - $159(24.5 \%)$

- $\quad$ Cesarean delivery - $209(32.2 \%)$

- With labour triggered - $117(64.3 \%) \%$

- Without - $65(35.7 \%)$

- Duration of ruptured membranes

- More than 18 hours - $156(26.8 \%)$

- $\quad$ More than 48 hours - 85 (14.6\%)

The pregnancies have different evolution and complications according to the modality of obtaining the pregnancy. The pregnancies obtain by ART procedures are more exposed to obstetrical complications but usually they benefit from a better follow up during the pregnancy. The differences between pregnancies obtained in a natural way or by ART procedures are presented in table no. 6 .

Table no. 6. The comparative data between ART and natural pregnancies

\begin{tabular}{|l|l|l|l|}
\hline & ART & Natural & p \\
\hline Number & 34 & 618 & \\
\hline Gestation age & $29,4+/-2,5$ & $29,6+/-2,4$ & 0,652 \\
\hline Weight & 1315,7 & 1349 & 0,626 \\
\hline Mother age & 31,2 & 28,17 & 0,008 \\
\hline Gestations & 1,8 & 3,2 & 0,001 \\
\hline Parity & 1,5 & 2,4 & 0,003 \\
\hline No. of cortisone doses & 3,8 & 2,7 & $<0,001$ \\
\hline Gender & Male 47,1\% & Male 58,5\% & 0,187 \\
\hline Small for gestational age & $38,2 \%$ & $52,4 \%$ & 0,638 \\
\hline Diabetes & 0 & 4 & 0,019 \\
\hline High blood pressure & 6 & 42 & 0,299 \\
\hline Preeclamsia/eclamsia & 0 & 6 & 0,546 \\
\hline Bleeding & 0 & 56 & 0,006 \\
\hline Imminent preterm delivery & $22(64,7 \%)$ & $152(24,7 \%)$ & 0,001 \\
\hline Urinary infections & 0 & 36 & 0,141 \\
\hline Corioamniotitis & 0 & 6 & 0,564 \\
\hline Presentation dystocia & $35,3 \%$ & $23,3 \%$ & 0,133 \\
\hline Cesarean section & $64,7 \%$ & $30,4 \%$ & 0,001 \\
\hline $\begin{array}{l}\text { Spontaneous rupture of } \\
\text { membranes more 18 hours }\end{array}$ & $17,6 \%$ & $25,8 \%$ & 0,287 \\
\hline $\begin{array}{l}\text { Spontaneous rupture of } \\
\text { membranes more 18 hours }\end{array}$ & $5,9 \%$ & $14,3 \%$ & 0,167 \\
\hline Corticotherapy & $82,4 \%$ & $55,4 \%$ & 0,002 \\
\hline Full doses corthicotherapty & $79 \%$ & $41,3 \%$ & \\
\hline
\end{tabular}

There are different types of evolution and prognostic, some of them with statistical significance between single pregnancies and twin pregnancies. The data are presented in table no. 7

Table no. 7. The comparative data between twin and single pregnancies

\begin{tabular}{|l|l|l|l|}
\hline & Twins & Single & p \\
\hline Number & 165 & 483 & \\
\hline Gestation age & $29,4+/-2,2$ & $29,5+/-2,4$ & 0,113 \\
\hline Weight & 1359,1 & 1343 & 0,646 \\
\hline Mother age & 28,8 & 28,0 & 0,180 \\
\hline Gestations & $2,9+/-2,4$ & $3,2+/-2,6$ & 0,147 \\
\hline Parity & $2,6+/-1,9$ & $2,3+/-2,6$ & 0,419 \\
\hline No. of cortisone doses & 2,1 & $2,8+/-1,4$ & $<0,552$ \\
\hline Gender & Male $60 \%$ & Male 57,1\% & 0,099 \\
\hline Small for gestational age & $46,1 \%$ & $53,6 \%$ & 0,242 \\
\hline Diabetes & 0 & 9 & 0,268 \\
\hline High blood pressure & 9 & 39 & 0,327 \\
\hline Preeclamsia/eclamsia & 3 & 16 & 0,620 \\
\hline Bleeding & 4 & 52 & 0,676 \\
\hline Imminent preterm delivery & $42(26,5 \%)$ & $131(27,1 \%)$ & 0,035 \\
\hline Urinary infections & 4 & 33 & 0,037 \\
\hline Corioamniotitis & 1 & 5 & 0,620 \\
\hline Presentation dystocia & $37 \%$ & $20,3 \%$ & 0,001 \\
\hline Cesarean section & $35,2 \%$ & $31,1 \%$ & 0,331 \\
\hline $\begin{array}{l}\text { Spontaneous rupture of } \\
\text { membranes more } 18 \text { hours }\end{array}$ & $14 \%$ & $29,1 \%$ & 0,001 \\
\hline $\begin{array}{l}\text { Spontaneous rupture of } \\
\text { membranes more } 48 \text { hours }\end{array}$ & $6,1 \%$ & $16,4 \%$ & 0,001 \\
\hline Corticotherapy & $88 \%$ & $58,2 \%$ & 0,279 \\
\hline Full doses corthicotherapty & $42,7 \%$ & $44,8 \%$ & 0,724 \\
\hline ART & $17,6 \%$ & $1 \%$ & 0,001 \\
\hline & & & \\
\hline
\end{tabular}

AMT, vol. 26, no. 4, 2021, p. 62 


\section{CLINICAL ASPECTS}

\section{DISCUSSIONS}

Analysing the data presented we have found significant number of premature delivery under 32 weeks of gestation. The average gestational age is about 29 weeks and the average weight is according to the gestational age.

Analysing each case, we have found that a significant proportion of the new-born $-54,6 \%$ were small for gestational age. Small for gestational age can be caused, usually by the pathology found as being associated or being the etiology of the prematurity. The most frequent pathology involved in low weight at birth are preeclampsia, chronic hypertension associated with preeclampsia, and the presumption of developing intrauterine growth restriction can be predictive by ultrasound scanning and monitoring. The studies presented in the literature shows a good sensitivity and specificity to ultrasound scan for fetal growth.(3)

Analysing the maternal age, as it was expected the most frequent maternal age is between 19-35 years, the age of maximum fertility, when most pregnancies are registered. There is also a high incidence for infantile pregnancies and for advanced maternal age where medical factors can be involved in the incidence of prematurity. One of the most frequent pathology for infantile pregnancy is premature delivery.(4)

Advanced maternal age is usually associated with chronic disease such as diabetes, chronic hypertension, renal and cardiovascular chronic disease also associated with high grade of prematurity, spontaneous or iatrogenic by obstetrical interventions for vital interest of the fetus or of the mother.(5)

An important factor involved in prematurity is the modality of obtaining a pregnancy. Assisted reproductive techniques are involved in the incidence of prematurity in two major circumstances. One is for single fetus pregnancies obtained by in vitro fertilization (IVF) where the factors are intricated considering advanced maternal age, discussed previously and the other is the perinatal pathology induced by the method itself. IFV pregnancies have higher rate of premature delivery, with new-born admission in intensive care units and congenital malformations. The higher incidence of congenital malformations is usually associated with intracitoplasmatic sperm injection.(6)

IVF pregnancies are also associated with high grade of twin pregnancies which, by itself is responsible for a high rate of premature delivery. In the last twenty years we are assisting to a twin pandemic, and sometimes even higher grades multiple pregnancies. The main reasons are the development of ART and the average advanced maternal age, both factors being responsible for multiple pregnancies. ART is involved by multiple oocytes during ovulation induction, by transferring more than one embryo and by the high fragility of the eggs transferred during IVF procedures. In many cases IVF is associated with advanced maternal age. If ART is causing usually dichorionic twins, single embryo-transfer and advanced maternal age is responsible for monochorionic twins, with a poorer prognosis than dichorionic pregnancies. $(7,8,9)$

Cortico-therapy is, in our days, unanimously accepted as being a major progress in premature preparation of the newborn, with a better outcome and prognosis. In all the cases, excepting few cases with advanced labour, cortico-therapy was administrated, in the majority of the cases. The initiation of cortico-therapy was present in almost all cases but a complete cure consisting of 4 doses of a cortisone drug was administrated only in $25 \%$ of the cases. The average duration of time from cortico-therapy was about 30 hours, usually enough for the prophylaxis of new born respiratory distress. The benefits of cortico-therapy are largely recognized in literature data. $(10,11,12)$

If we compare and statistically analyse all the factors presented in the results for the modality of obtaining the pregnancy we can see that there are significantly differences between those two categories for the number of cortisone doses and for the incidence of the caesarean section, maternal age, number of gestations, parity, gestational diabetes, bleeding and imminent preterm delivery.

The number of the cortisone dosses is influenced by two factors; - the length of the hospitalization before onset of labour and the prophylactic administration of cortisone before the emergency occurs. Usually, ART pregnancies are considered high risk pregnancies and the follow up is more adequate comparative with natural pregnancies. In ART pregnancies, as in our country transferring two blastocysts is still a routine the twin pregnancies are more often and this is resulting in higher risk of premature delivery.(13,14) Knowing the twin pregnancy is at high risk of prematurity obstetricians are usually administrating cortico-therapy when certain signs are predicting the premature possible birth. The most important signs are shortening and softening of the cervix and higher uterine activity.(15) Recognizing these signs is usually followed by full dose of cortico-therapy and a significant reduction of new born respiratory distress.

Another significant difference is in the modality of delivery for ART pregnancies and for natural conceived pregnancy. For the ART pregnancies the incidence of the caesarean section is more than double.(16) There are a lot of factors to be considered and the first is the higher incidence of multiple pregnancies, especially twin pregnancies with a higher incidence of abnormal presentations such as breech and transvers presentation of one of the fetuses. $(17,18)$ Advanced maternal age is more frequent, the ART pregnancies usually are conceived after a long period of infertility, this long period being associated with progressive advance in the maternal age. Advanced maternal age itself is a high risk pregnancy and the general and different organ pathology associated or induced by the pregnancy are more frequent found in this category of pregnancies.(19)

The other factors analysed between natural conceived and ART pregnancies: gestation range, gestational age, weight, gender, small for gestational age, diabetes, high blood pressure, bleeding, maternal infections, spontaneous rupture of the membranes did not have significantly statistical differences.

Analysing the differences between single and twin pregnancies we could find significantly differences between ART conceived pregnancies, the incidence of the premature rupture of the membranes and fetal or labour dystocia.

Premature rupture of membranes has a double incidence in twin pregnancies, also described in literature data.(20) Twin pregnancies are much often associated with cervical softening and ripening, much earlier than in single pregnancies. Cervical dilatation is more often seen in twin pregnancies due to rapid increase in uterus size and premature formation of the lower segment of the uterus. Associations of local infections such as Streptococcus B or Ureaplasma infections are inducing a local inflammatory response with degradation of the patency of the membranes and premature rupture. $(21,22)$

Labour dystocia and abnormal presentations such as breech, transverse or oblique position of the fetuses are more frequent associated with twin pregnancy and this type of pathology is a common indication of caesarean section.(23)

All the other parameters considered for a comparison between single and twin pregnancies did not have statistical significance.

1. Prematurity is a public health problem due to the large 


\section{CLINICAL ASPECTS}

number of new-borns, especially those with gestational age under 32 weeks of gestation.

2. The main causes of prematurity under 32 weeks were HTAIS, pregnancy bleeding and infectious complications.

3. Prophylactic cortisone therapy is improving fetal outcome by preventing new born respiratory distress and is a routine practice in our clinic.

4. In the comparative analysis between multiple and single pregnancy there are significant differences in maternal age, in terms of premature rupture of membranes and fetal dystocia, and ART conceived pregnancies.

5. In the comparative analyses between natural conceived pregnancies and ART pregnancies we have found statistically significant differences the number of cortisone doses and for the incidence of the caesarean section, maternal age, number of gestations, parity, gestational diabetes, bleeding and imminent preterm delivery.

\section{REFERENCES}

1. Bos LT, Tijms J. The incidence of prematurity or low birth weight for gestational age among children with dyslexia. Acta Paediatrica. 2012;101(11):e526-8 doi:http://dx.doi.org.am.e-nformation.ro/10.1111/j.16512227.2012.02806.x.

2. Fernandes M, Silva Melo M, dos Santos AG, Santiago AKC. Prognosis of newborns in neonatal intensive care units: An integrative review. Revista De Pesquisa, Cuidado é Fundamental Online. 2019;11(3):748-755. doi:http://dx.doi.org.am.e-nformation.ro/10.9789/21755361.2019.v11i3.748-755.

3. Ciobanu A, Khan N, Syngelaki A, Akolekar R, Nicolaides KH. Routine ultrasound at 32 0RW1S34RfeSDcfkexd09rT2vs1RW1S34RfeSDcfkexd09r T2 36 weeks' gestation: Prediction of small-for-gestational-age neonates. Ultrasound in Obstetrics \& Gynecology. 2019;53(6):761-768. doi:http://dx.doi.org.am.e-

nformation.ro/10.1002/uog.20258.

4. Dunbar J, Sheeder J, Lezotte D, Dabelea D, Stevens-Simon C. Age at menarche and first pregnancy among psychosocially at-risk adolescents. American Journal of Public Health. 2008;98(10):1822-4.

5. Lean SC, Heazell AL, Mills TA, Boscolo-Ryan J, Peacock, L, Jones RL. PP.08 Manchester advanced maternal age study (MAMAS) - does an ageing maternal environment and altered placental function explain higher risk of poor pregnancy out come in advanced maternal age? Archives of Disease in Childhood. Fetal and Neonatal Edition. 2013;98 doi:http://dx.doi.org.am.e-

nformation.ro/10.1136/archdischild-2013-303966.289.

6. Nouri K, Ott J, Stoegbauer L, Pietrowski D, Frantal S, Walch K. Obstetric and perinatal outcomes in IVF versus ICSI-conceived pregnancies at a tertiary care center - a pilot study. Reproductive Biology and Endocrinology. 2013;11:84. doi:http://dx.doi.org.am.enformation.ro/10.1186/1477-7827-11-84.

7. Suzuki S, Miyake H. Perinatal outcomes of elderly primiparous dichorionic twin pregnancies conceived by in vitro fertilization compared with those conceived spontaneously. Archives of Gynecology and Obstetrics. 2010;281(1):87-90. nformation.ro/10.1007/s00404-009-1083-3.

8. Dadhwal V, Sharma AK, Deka D, Chawla L, Agarwal N. Selective fetal reduction in monochorionic twins: Preliminary experience. Journal of the Turkish German Gynecological Association. 2019;20(2):79-83. doi:http://dx.doi.org.am.e- nformation.ro/10.4274/jtgga.galenos.2018.2018.0052.

9. Yildirım E. Spontaneous triplet pregnancy and trap sequence, case report. BMC Pregnancy and Childbirth. 2019;19.doi:http://dx.doi.org.am.enformation.ro/10.1186/s12884-019-2484-3.

10. Saugstad OD, Kwinta P, Wollen EJ, Bik-Multanowski M, Madetko-Talowska A, Jaga M, Pietrzyk JJ. Impact of antenatal glucocorticosteroids on whole-genome expression in preterm babies. Acta Paediatrica. 2013;102(4):349-55. doi:http://dx.doi.org/10.1111/apa.12166.

11. Regaieg I, Amel BH, Charfi M, Regaieg C, Bouraoui A, Hmida N, Gargouri A. P635 Impact of antenatal corticosteroid therapy on the neonatal prognosis of preterm infants born before 33 weeks of amenorrhea. Archives of Disease in Childhood. 2019;104 doi:http://dx.doi.org/10.1136/archdischild-2019-epa.966.

12. Boulet SL, Schieve LA, Nannini A, Ferre C, Devine O, Cohen B, Macaluso M. Perinatal outcomes of twin births conceived using assisted reproduction technology: A population-based study[sup]. Human Reproduction. 2008;23(8):1941-8.

doi:http://dx.doi.org/10.1093/humrep/den169.

13. Luke B, Stern JE, Hornstein MD, Kotelchuck M, Diop H, Cabral H, Declercq ER. Is the wrong question being asked in infertility research? Journal of Assisted Reproduction and Genetics. 2016;33(1):3-8 doi:http://dx.doi.org/10.1007/s10815-015-0610-3.

14. Slattery MM, Morrison JJ. Preterm delivery. The Lancet. 2002;360(9344):1489-1497. doi:http://dx.doi.org/10.1016/S0140-6736(02)11476-0.

15. Carreno CA, Chauhan SP. Caesarean section is the safest mode of delivery for extremely preterm breech singleton infants: FOR: Caesarean delivery of extremely preterm breech singletons: An international journal of obstetrics and gynaecology. Bjog. doi:http://dx.doi.org/10.1111/1471-0528.15037.

16. Caughey AB. Elective cesarean delivery: When is it justified? Journal of Perinatology. 2006;26(1):1-2. doi:http://dx.doi.org/10.1038/sj.jp.7211421.

17. Ebner F, Friedl TWP, Leinert E, Schramm A, Reister F, Lato K, DeGregorio N. Predictors for a successful external cephalic version: A single centre experience. Archives of Gynecology and Obstetrics. 2016;293(4):749-755. doi:http://dx.doi.org/10.1007/s00404-015-3902-z.

18. Benjamin B, Ishaque U, Chrusciel J, Bonneau S, Gabriel, $\mathrm{R}$, Graesslin O. Influence of the external cephalic version attempt on the cesarean section rate: Experience of a type 3 maternity hospital in France. Archives of Gynecology and Obstetrics. 2021;303(2):443-454. doi:http://dx.doi.org/10.1007/s00404-020-05765-2.

19. Kenny LC, Lavender T, McNamee R, Sinéad M O’Neill, Mills T, Khashan AS. Advanced maternal age and adverse pregnancy outcome: Evidence from a large contemporary cohort. PLoS One. 2013;8(2):doi:http://dx.doi.org/10.1371/journal.pone.00565 83.

20. Epstein FH, Parry S, Jerome FMD. Premature rupture of the fetal membranes. The New England Journal of Medicine. 1998;338(10):663-670. Retrieved from https://www.proquest.com/scholarly-journals/prematurerupture-fetal-membranes/docview/223949696/se2? accountid $=136549$.

21. Tajik P, Ham DP, Zafarmand MH, Hof M, Morris J, Franssen M, Mol B. Using vaginal group B Streptococcus colonisation in women with preterm premature rupture of membranes to guide the decision for immediate delivery: A secondary analysis of the PPROMEXIL trials: An 


\section{CLINICAL ASPECTS}

international journal of obstetrics and gynaecology. Bjog. 2004;121(10):1263-1272.

doi:http://dx.doi.org/10.1111/1471-0528.12889.

22. Suzuki Y, Horie K, Yada Y, Kono Y, Hirashima C, Usui, $\mathrm{R}$, Ohkuchi A. Vaginal ureaplasma species increase chorioamnionitis in very preterm infants with preterm premature rupture of the membranes at $<28$ weeks of gestation. European Journal of Clinical Microbiology and Infectious Diseases. 2018;37(12):2371-2380. doi:http://dx.doi.org/10.1007/s10096-018-3385-5.

23. Soliman SR, Burrows RF. Cesarean section: Analysis of the experience before and after the national consensus conference on aspects of cesarean birth: CMAJ. Canadian Medical Association. Journal. 1993;148(8):1315-20. Retrieved from https://www.proquest.com/scholarlyjournals/cesarean-section-analysis-experience-beforeafter/docview/204963950/se-2?accountid=136549. 